\title{
Simulation Study of Citronellol-geraniol Rectification Tower Based on Aspen Plus Software
}

\author{
Qiu Chen ${ }^{1}$, Lisha Feng ${ }^{1}$ \\ ${ }^{1}$ Yunnan Open University, ${ }^{1}$ Yunnan Vocational \& Technical College of National Defense Industry
}

\begin{abstract}
Aspen Plus is a large-scale chemical simulation software based on steady-state chemical simulation, optimization, sensitivity analysis and economic evaluation. It can analyze the planning, research, development and technical reliability of chemical processes. High-purity citronellol and geraniol, the main high-value components of citronella oil, make the rectification and purification process difficult due to their boiling point and heat sensitivity, with high separation cost and poor effect, resulting in low economic benefits. This paper uses Aspen Plus software to estimate the physical properties of citronellol and geraniol system through known structural formula and room temperature boiling point; uses citronellol-geraniol vapor-liquid equilibrium experimental data to select physical properties analytical methods of Aspen Plus software; conducts process design and simulation of the high vacuum separation of citronellol and geraniol by using DSTWU simple simulation tower and RadFrac strict simulation tower respectively, gets the process parameters of citronellol and geraniol distillation tower, checks the separation process, and optimizes the separation conditions, which provide support for using industrial production in the high-purity separation of citronella oil system.
\end{abstract}

Project Number: 2015Y367

The chemical process simulation is to "reproduce" the actual chemical production process through the computer, but this reproduction does not involve the actual installation, equipment and energy consumption, so the chemical simulation personnel are free to carry out discussion and analysis on different schemes and process conditions on the computer [1]. It saves a lot of capital, operation cost and time, can comprehensively analyze and accurately evaluate the optimization of chemical production process's rectification, absorption, reaction, heat exchange unit and process flow and also can analyze the planning, study, development and technical reliability of the chemical process. As a large-scale chemical simulation software based on steady-state chemical simulation, optimization, sensitivity analysis and economic evaluation, Aspen Plus has a rich database of physical properties, which can deal with inorganic, organic, non-ideal and high-polar complex systems. It specifically has the solution method combining the equation solving method and sequential modular method, sensitivity analysis, automatic sorting, multiple convergence methods, as well as reporting functions[2]. Currently, as a powerful standard large-scale process simulation software, Aspen Plus has been widely used in many industrial fields such as chemical industry, oil refining, coal, metallurgy, environmental protection, power, energy conservation, medicine, food and so on[34].

Natural essential oil is an important natural spice, mainly derived from the flowers, branches, roots and buds of natural aromatic plants. It is an oily substance with certain aroma and volatility extracted from various aromatic plants by a series of processing methods. Since some fragrant components of natural spices, although they are trace amounts, can impart special effects on the aroma, synthetic fragrances have not been used to replace them so far[5]. Plants of citronella family are important perennial herbs. There are about 40 species of this family in the world, and most of them are growing in Yunnan Province of China. The active ingredient containing natural aroma extracted from the roots, stems and leaves of plants of citronella family by steam distillation is the citronella crude oil. Citronellol and geraniol in citronella crude oil are important spices, and their prices have risen all the way due to low extraction yield, high cost and complicated process conditions.

This paper uses Aspen Plus chemical process simulation software to design and simulate the high vacuum distillation process of citronellol and geraniol in citronella crude oil, carries out sensitivity analysis and sets parameters to achieve the purpose of optimizing the distillation process, thus providing strong data support for the production process. 


\section{Using ASPEN PLUS software to determine the physical property analysis method}

\subsection{Properties of citronella oil}

As a representative natural aromatic oil, citronella oil is mainly composed of citronellal, citronellol and geraniol, while citronellol is mainly found in citronella oil as dextro-citronellol. And their main physical and chemical properties and structural formulas are shown in Table 1.

Table 1. The Physical Properties and the Chemical properties of Citronellol, Geraniol.

\begin{tabular}{|c|c|c|}
\hline $\begin{array}{c}\text { Name } \\
\text { English } \\
\text { name }\end{array}$ & Citronellol & Geraniol \\
\hline $\begin{array}{c}\text { Molecular } \\
\text { formula }\end{array}$ & $\mathrm{C}_{10} \mathrm{H}_{20} \mathrm{O}$ & $\mathrm{C}_{10} \mathrm{H}_{18} \mathrm{O}$ \\
\hline $\begin{array}{c}\text { Chemical } \\
\text { Name }\end{array}$ & $\begin{array}{c}3,7- \\
\text { dimethyl- } \\
\text { 6-octene-1 } \\
\text { alcohol }\end{array}$ & $\begin{array}{c}\text { 2,6- } \\
\text { dimethyl- } \\
2,6- \\
\text { octadien- } \\
8 \text {-alcohol }\end{array}$ \\
\hline $\begin{array}{c}\text { Molecular } \\
\text { weight }\end{array}$ & 156.27 & 154.25 \\
\hline $\begin{array}{c}\text { Atmosphe } \\
\text { ric boiling } \\
\text { point } /{ }^{\circ} \mathrm{C}\end{array}$ & 225 & \\
\hline $\begin{array}{c}\text { Structural } \\
\text { formula }\end{array}$ & $\mathrm{CH}_{\mathrm{CH}} \mathrm{OH}$ \\
\hline
\end{tabular}

\subsection{Physical property method selection}

Aspen plus software provides selection method models of various physical properties, such as ideal model, state equation model, activity coefficient model and special model. They can be used to calculate thermodynamic properties and transfer properties, and choosing the right physical property method is the key to the accuracy of the simulation results. In the process of selecting physical property method, the ideal degree and operating conditions of the physical system should be fully considered. Generally, it can be selected according to the characteristics of the physical system and the operating temperature and pressure, or selected based on the software. According to the characteristics and separation conditions of citronellol and geraniol system, the empirical method is used to screen out the physical property analysis methods of WILSON, NRTL and UNIQUAC. However, which physical property method is more suitable for the simulation of citronellol-geraniol system in the specific simulation process is a question. The application of different methods has a very large impact on the simulation results. Therefore, before the unit simulation, it is necessary to use the physical property analysis function provided by Aspen plus software to fit the WILSON, NRTL and UNIQUAC methods. The binary vapor-liquid equilibrium data of citronellol and geraniol are compared with the vaporliquid equilibrium experimental data of citronellol and geraniol to verify the accuracy of the physical property analysis method, in order to find a more suitable physical property analysis method[6-7].

\subsubsection{Vapor-liquid equilibrium experiment of citronellol and geraniol}

The raw materials of this experiment are selected from the crude oil produced by a perfumery factory in Yunnan and are prepared after laboratory preparation. The experimental equipment is a gas-liquid two-cycle vaporliquid equilibrium analyzer of model PILODIST VLE$10 \mathrm{D}$ produced in Germany. The operating pressure range is 4bar-1.0mbar (absolute value), the operating temperature range is less than $250{ }^{\circ} \mathrm{C}$, and the detection accuracy is 0 -1bar (absolute value). The temperature accuracy of gas and liquid phase displayed achieves $\pm 0.065 \mathrm{k}$. At least three sets of vapor-liquid phase equilibrium parallel samples are taken for analysis in the process of experiment. The analytical data are analyzed by GC-2014 gas chromatograph, PEG20000 capillary column, Shimadzu, Japan, and detector temperature is controlled at $240{ }^{\circ} \mathrm{C}$. The experimentally determined gasliquid equilibrium data of the citronellol-geraniol system are used to draw the vapor-liquid equilibrium phase diagram shown in Figure 1.

\subsubsection{Simulation and analysis of vapor-liquid equilibrium data of citronellol and Geraniol by NRTL, UNIQUAC and WILSON methods}

The citronella oil system is a non-stock material, and the Aspen plus software system lacks the relevant physical parameters of the system, so the physical properties of the two substances are estimated based on the standard boiling points of citronellol and geraniol before the physical property analysis, and the relevant data after estimation are saved to facilitate subsequent physical analysis and unit simulation[2]. This paper respectively uses NRTL, UNIQUAC and WILSON methods to simulate the vapor-liquid equilibrium data of citronellol and geraniol, as are shown in Figure 2, Figure 3 and Figure 4.

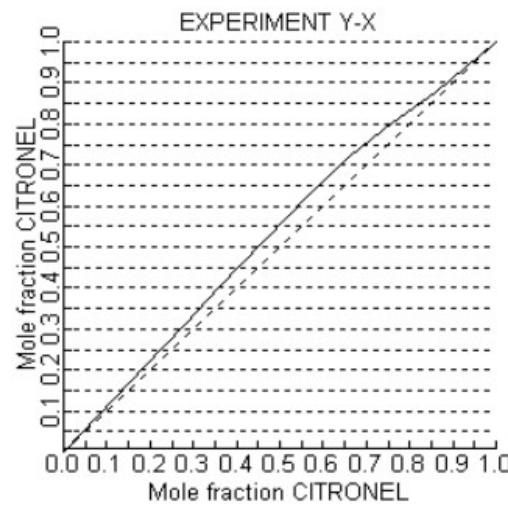

Figure 1. Vapor-liquid Equilibrium Phase Diagram of Citronellol and Geraniol (Experiment). 


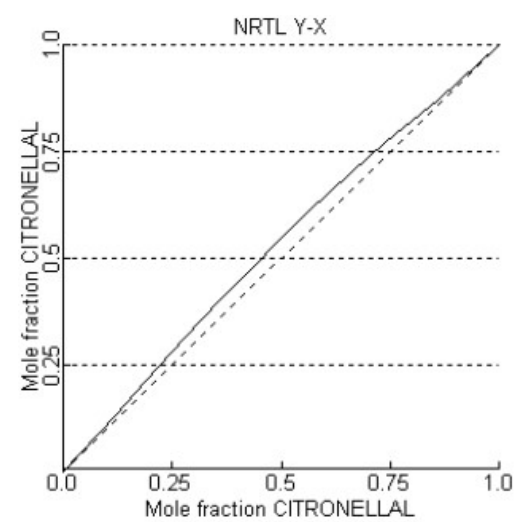

Figure 2. Vapor-liquid Equilibrium Phase Diagram of Citronellol and Geraniol (NRTL).

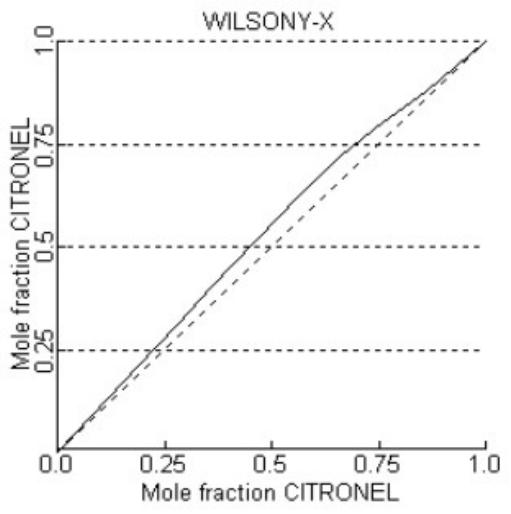

Figure 3. Vapor-liquid Equilibrium Phase Diagram of Citronellol and Geraniol (WILSON).

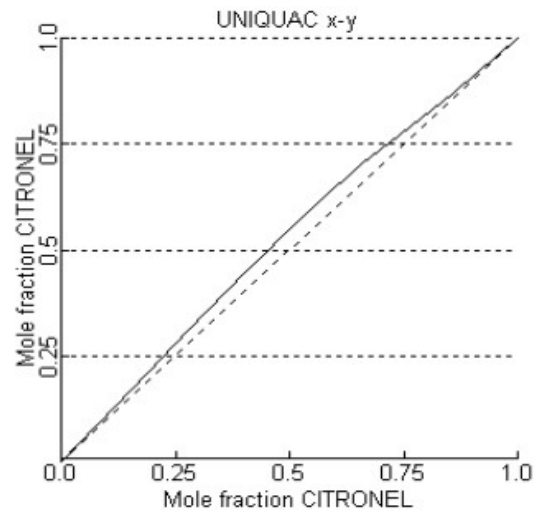

Figure 4. Vapor-liquid Equilibrium Phase Diagram of Citronellol and Geraniol (UNIQUAC).

The data regression system of the Aspen plus software is used to fit the three model parameters to the vapor-liquid equilibrium experimental data of the citronellol-geraniol system, and the results are shown in Table 2.

Table 2. Standard Deviation of Fitting Data of NRTL, UNIQUAC and WILSON Methods and Experimental Data.

\begin{tabular}{|c|c|c|c|c|}
\hline \multicolumn{2}{|c|}{$\begin{array}{c}\text { Component Standard } \\
\text { deviation }\end{array}$} & NRTL & UNIQUAC & WILSON \\
\hline Citronellol & Geraniol & 0.23562516 & 0.24375064 & 0.07323622 \\
\hline Geraniol & Citronellol & 0.60512384 & 0.12337526 & 0.79465072 \\
\hline
\end{tabular}

It can be seen from the data in Table 2 that the standard deviations of NRTL method and WILSON method sometimes are too large, and the data are relatively discrete, indicating that the simulated values of the two methods are sometimes quite different from the experimental data and the results differ a lot, thus affecting the simulation results; the standard deviation of the UNIQUAC method is small, and the dispersion is small, so the simulation accuracy of the UNIQUA method is better than that of the other two methods. Therefore, the subsequent simulation process uses the UNIQUAC physical property analysis method to conduct simulation design calculation.

\section{DSTWU simple simulation of citronellol-geraniol rectification tower}

In Aspen Plus 7.3, there are seven tower equipment analog design modules including DSTWU, Distl, SCFrac, RadFrac, MultiFrac, PetroFrac and Extract. DSTWU module is multi-component rectification simple design module, the accuracy of its design calculation is not high, and it is often used for preliminary design to determine the data like the reflux ratio, rectification tower, number of stages, condenser and reboiler load, etc., and can also provide suitable initial values for RadFrac strict rectification simulation analysis and optimization data[2].

The DSTWU simple design module is used to establish the simple design flow of the citronellolgeraniol rectification tower. The global setting, component input and setting physical property method to UNIQUAC are conducted in turn, and the initial values of other feed parameters and module parameters are shown in the table. 3. The difference in boiling point temperature of the citronellol-geraniol system is small, it can be seen from the vapor-liquid equilibrium phase diagram of Fig. 1 that the equilibrium curve is very close to the diagonal, and the separation is very difficult, so the initial separation requirement of citronellol and geraniol is set to 0.85 , the reflux ratio is set to 1.4 times, and the feed temperature is normal temperature.

Table 3. List of DSTWU Module Parameters and Feed Parameters

\begin{tabular}{|c|c|c|c|c|}
\hline $\begin{array}{c}\text { Serial } \\
\text { number }\end{array}$ & $\begin{array}{c}\text { Parameter } \\
\text { name }\end{array}$ & Unit & $\begin{array}{c}\text { Input the } \\
\text { parameter } \\
\text { value of } \\
\text { DSTWU } \\
\text { module }\end{array}$ & Remarks \\
\hline 1 & $\begin{array}{c}\text { Feed } \\
\text { temperature }\end{array}$ & ${ }^{\circ} \mathrm{C}$ & 25 & $\begin{array}{c}\text { Feed } \\
\text { parameter }\end{array}$ \\
\hline 2 & $\begin{array}{c}\text { Tower } \\
\text { pressure }\end{array}$ & $\mathrm{KPa}$ & 1.2 & $\begin{array}{c}\text { Feed } \\
\text { parameter }\end{array}$ \\
\hline 3 & $\begin{array}{c}\text { Feed flow } \\
\text { Fitronellol } \\
\text { composition }\end{array}$ & $\begin{array}{c}\mathrm{Kmol} / \mathrm{h} \\
\text { Frac }\end{array}$ & 50 & $\begin{array}{c}\text { Feed } \\
\text { parameter }\end{array}$ \\
\hline 5 & $\begin{array}{c}\text { Reflux ratio } \\
\text { Keeding }\end{array}$ & $\begin{array}{c}\text { Feed } \\
\text { parameter }\end{array}$ \\
\hline
\end{tabular}




\begin{tabular}{|c|c|c|c|c|}
\hline 6 & $\begin{array}{c}\text { Disillate } \\
\text { Mole fraction } \\
\text { of citronellol }\end{array}$ & $\begin{array}{c}\text { Mole- } \\
\text { Frac }\end{array}$ & $\begin{array}{c}0.85 \text { Tab.3 } \\
\text { List of } \\
\text { DSTWU } \\
\text { Module } \\
\text { Parameters } \\
\text { and Feed } \\
\text { Parameters }\end{array}$ & $\begin{array}{c}\text { Module } \\
\text { parameter }\end{array}$ \\
\hline 7 & $\begin{array}{c}\text { Bottom Mole } \\
\text { fraction of } \\
\text { geraniol }\end{array}$ & $\begin{array}{c}\text { Mole- } \\
\text { Frac }\end{array}$ & 0.85 & $\begin{array}{c}\text { Module } \\
\text { parameter }\end{array}$ \\
\hline
\end{tabular}

Table 4. DSTWU Simple Tower Simulation Results.

\begin{tabular}{|c|c|c|}
\hline Serial number & Parameter & Simulation result \\
\hline 1 & Minimum reflux radio & 11.68 \\
\hline 2 & $\begin{array}{c}\text { Minimum number of } \\
\text { stages }\end{array}$ & 30 \\
\hline 3 & Actual reflux radio & 16.35 \\
\hline 4 & Feed stage & 21 \\
\hline 5 & Number of actual stages & 48 \\
\hline 6 & $\begin{array}{c}\text { Distillate to feed } \\
\text { fraction }\end{array}$ & 0.388 \\
\hline 7 & Disillate temperature & $102.73^{\circ} \mathrm{C}$ \\
\hline 8 & Bottom temperature & $105.13^{\circ} \mathrm{C}$ \\
\hline
\end{tabular}

The related data of the simple simulation calculation by using the DSTWU model are shown in Table 4, and can be used as the input of the initial value of the RadFrac strict distillation model to facilitate the calibration and optimization of the distillation process.

\section{Citronellol-geraniol rectification Tower of RadFrac strict simulation}

RadFrac is a strict model for simulating all multi-stage gas-liquid separation operations including general rectification, absorption, stripping, extractive rectification and azeotropic rectification. Whether it is two-phase, three-phase, narrow-boiling point, wide-boiling point physical system, or ideal, non-ideal physical system, the simulation effect is good. The citronellol-geraniol system is a two-phase narrow-boiling system, so it is necessary to use the RadFrac strict model to check the simulation results of the DSTWU model.

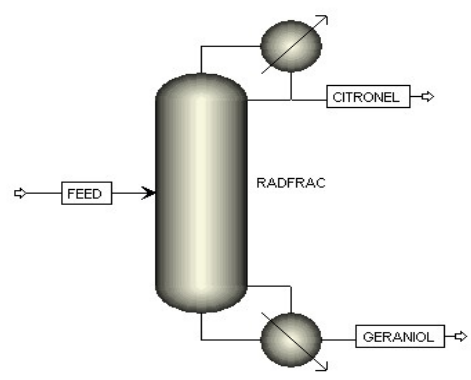

Figure 5. The flowsheet of RadFrac.

The process of citronellol-geraniol rectification tower is established by using the RadFrac strict model, as is shown in Figure 5. Input the parameters obtained by the DSTWU simple calculation module: the actual reflux ratio is 16.35 , the theoretical stage number is 48 , the feed stage is the $21 \mathrm{st}$ block, distillate to feed Mole fraction is 0.388 , and the operating pressure is $1.2 \mathrm{KPa}$, and conduct simulation calculation. Table 5 is a comparison table of DSTWU and RadFrac calculation results. From the calibration results, it can be seen that the concentration of citronellol in the top product and the bottom product differs greatly, so the data calculated by DSTWU are only for reference. Since the citronellol-geraniol system is a narrow-boiling system, the data using the RadFrac strict model for simulation analysis is more reliable. By analysis, the separation purity of geraniol is higher in this system, and if the separation purity of citronellol needs to be improved, the conditions of the separation process should be optimized.

Table 5. Comparison of the Calculation Results of DSTWU and RadFrac.

\begin{tabular}{|c|c|c|c|}
\hline Serial number & Parameter & DSTWU & RadFrac \\
\hline 1 & $\begin{array}{c}\text { Disillate } \\
\text { temperature }\end{array}$ & $102.73^{\circ} \mathrm{C}$ & $102.65^{\circ} \mathrm{C}$ \\
\hline 2 & $\begin{array}{c}\text { Bottom } \\
\text { temperature }\end{array}$ & $105.13^{\circ} \mathrm{C}$ & $105.64^{\circ} \mathrm{C}$ \\
\hline 3 & $\begin{array}{c}\text { Disillate } \\
\text { Mole fraction } \\
\text { of citronellol }\end{array}$ & 0.85 & 0.771 \\
\hline 4 & $\begin{array}{c}\text { Bottom Mole } \\
\text { fraction of } \\
\text { geraniol }\end{array}$ & 0.85 & 0.933 \\
\hline
\end{tabular}

\section{Sensitivity analysis}

Using the sensitivity analysis tool in Aspen plus software, changing some key variables or design variables can achieve the purpose of optimizing design data[2]. As is shown in Fig. 6, the optimum feed position can be found by analyzing the relation curve of the thermal load of the reboiler changing with the feed position under different theoretical stages.

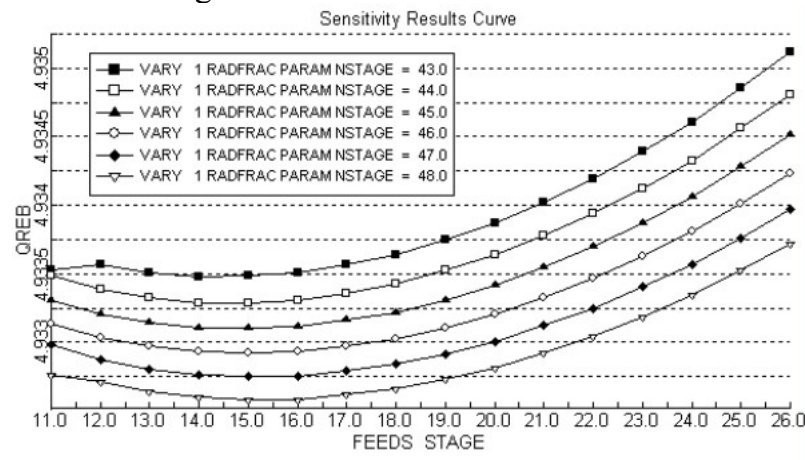

Figure 6. Variation of Thermal Load of Reboiler with Feed Position under Different Theoretical Stages.

The number of stages has increased from 43 to 48 . Although the number of stages has increased, there is always a lowest heat load, that is, when the feed stage is the 15 th stage, the thermal load of the reboiler required is the least. The 15th stage is used as the feed stage, and after re-calibrating the data with the RadFrac strict model, it is found that the change of the feed stage position has little effect on the products of the tower top and tower bottom while the number of theoretical stages remain unchanged. But the thermal consumption of the reboiler can be greatly reduced, thus reducing the operating cost, so the optimum feed stage position is the 15th stage; as the number of theoretical stages increases, the thermal load at the optimal feed position is reduced, but 
considering the increase in the number of stages will increase the tower height, thereby increasing the manufacturing cost of the equipment, the increase in the number of stages should be appropriate, and the importance of optimization of the two key parameters, the number of stages and the reflux ratio, is obvious.

The reflux ratio is the core parameter in the design of the rectification tower, and its size directly affects the number of stages, the structural size of the stages and the consumption of heating steam and cooling water. Too large reflux ratio may increase the consumption of heating steam and cooling water, operation cost and investment cost, and weaken the adjustment of the separation ability of the tower. As is shown in Fig. 7, when reflux ratio is changed from 14 to 18 at the beginning, if the number of stages is constant, increasing the reflux ratio is advantageous for increasing the concentration of geraniol in the tower bottom; when the reflux ratio changes from 18 to 24 , the concentration variation of geraniol in the tower bottom gradually slows down, while the thermal load consumed by the reboiler increases very fast; if the reflux ratio remains unchanged, the increase of product composition can only be achieved by increasing the number of stages. Taking the composition of geraniol in the tower bottom as 0.95 as an example, if the reflux ratio remains unchanged, 60 stages are required to achieve the separation requirement; if the reflux ratio is increased to 18,54 stages are required to complete the separation task, and when the reflux ratio exceeds 18 , the composition of the product changes slowly; if the number of stages remains unchanged, and it is necessary to increase the reflux ratio to 24 to achieve the separation requirement, while excessive reflux ratio will result in large production cost, which is uneconomical. In summary, when the composition of the geraniol product of the tower bottom is 0.95 , the reflux ratio is selected to be 18 , and the number of stages is 54 , which is a relatively good solution. The final optimization results are shown in Table 6, and the composition of the citronellol in the tower top is close to 0.8 at this time.

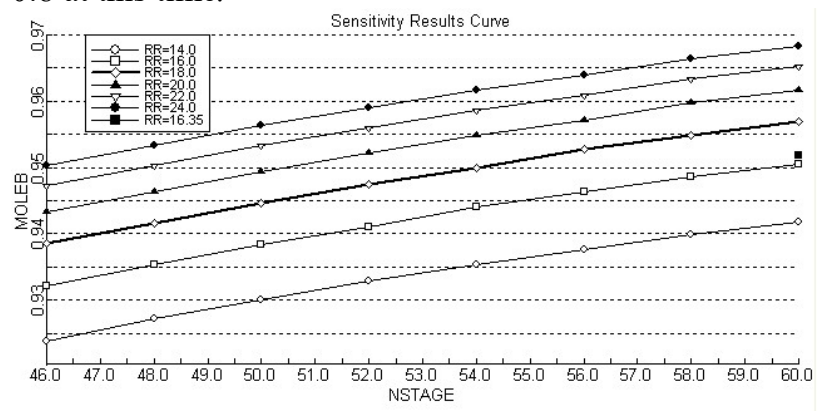

Figure 7. Variation Curve of the Composition of Geraniol in the Tower Bottom with the Number of Stages and the Reflux Ratio.

Table 6. Optimization Simulation Results of Citronellol-geraniol High Vacuum Rectification Tower.

\begin{tabular}{|c|c|c|}
\hline Serial number & Parameter & Simulation result \\
\hline 1 & Actual reflux radio & 18 \\
\hline 2 & feed stage & 15 \\
\hline
\end{tabular}

\begin{tabular}{|c|c|c|}
\hline 3 & $\begin{array}{c}\text { number of actual } \\
\text { stages }\end{array}$ & 54 \\
\hline 4 & $\begin{array}{c}\text { distillate to feed } \\
\text { Mole fraction }\end{array}$ & 0.388 \\
\hline 5 & Disillate temperature & $102.6^{\circ} \mathrm{C}$ \\
\hline 6 & Bottom temperature & $105.2^{\circ} \mathrm{C}$ \\
\hline 7 & $\begin{array}{c}\text { Mole fraction of } \\
\text { citronellol }\end{array}$ & 0.95 \\
\hline 8 & $\begin{array}{c}\text { Mole fraction of } \\
\text { geraniol }\end{array}$ & 0.797 \\
\hline
\end{tabular}

\section{Conclusion}

(1) The physical properties of citronellol and geraniol are estimated by using the physical property estimation system in Aspen Plus software, which provides basic data for the subsequent simulation process; NRTL, UNIQUAC and WILSON physical property analysis methods are used to simulate citronellol-geraniol vaporliquid equilibrium data, the data are compared with the citronellol-geraniol vapor-liquid equilibrium experimental data, and the UNIQUAC method is found more suitable for citronellol-geraniol separation simulation.

(2) The initial data of the citronellol-geraniol high vacuum distillation simulation are found by DSTWU simple distillation simulation in Aspen Plus software (Table 4).

(3) The results of DSTWU simple distillation simulation are verified and optimized by the RadFrac strict distillation model in Aspen Plus software (Table 6), which provides data support for the separation and purification of citronella oil.

\section{References}

1. Xue Kechuang. Using Aspen Plus 7.3 for Strict Distillation Process Simulation. Shandong Chemical Industry, 2014

2. Sun Lanyi. Chemical Process Simulation Training: Aspen Plus Tutorial [M]. Beijing: Chemical Industry Press, 2012

3. ASPENTechnologyInc. ASPENPLUSUSERGUIDE, 1994.

4. Xie Anjun, Liu Shijun, Zhang Huayan, et al. Large Chemical Process Simulation Software - AspenPlus [J]. Chemical Engineering of Oil and Gas, 1995, 24(4): 247-251

5. Luo Jinyue, An Xinnan. Processing Process of Plant Essential Oils and Natural Pigments. Chemical Industry Press, 2005.1

6. Zhang Zhishan, Yang Chaolong, Application of Aspen Plus in Chemical Industry. Guangdong Chemical Industry, 2012

7. Wang Li, Fu Wen, Li Jian. Simulating the Four-tower Distillation Process of Cassava Anhydrous Ethanol with Aspen Plus. Liquor-Making Science and Technology, 2013 